\title{
Evaluation of the DOAC-Stop ${ }^{\circledR}$ Procedure to Overcome the Effect of DOACs on Several Thrombophilia Screening Tests
}

\author{
Julien Favresse ${ }^{1}$ Benjamin Lardinois ${ }^{1}$ Lina Sabor $^{1}$ Bérangère Devalet ${ }^{2}$ Julie Vandepapeliere ${ }^{2}$ \\ Maximilien Braibant ${ }^{3}$ Sarah Lessire ${ }^{4}$ Bernard Chatelain ${ }^{1}$ Hugues Jacqmin ${ }^{1}$ Jonathan Douxfils ${ }^{5,6}$ \\ François Mullier ${ }^{1}$
}

\footnotetext{
1 Université Catholique de Louvain, CHU UCL Namur, Hematology Laboratory, Namur Thrombosis and Hemostasis Center, NARILIS, Yvoir, Belgium

${ }^{2}$ Department of Hematology, CHU UCL Namur, Namur Thrombosis and Hemostasis Center, Université Catholique de Louvain, Yvoir, Belgium

${ }^{3}$ Department of Pharmacy, CHU UCL Namur, Namur Thrombosis and Hemostasis Center, Université Catholique de Louvain, Yvoir, Belgium

${ }^{4}$ Department of Anesthesiology, CHU UCL Namur, Namur Thrombosis and Hemostasis Center, Université Catholique de Louvain,

Yvoir, Belgium

${ }^{5}$ Department of Pharmacy, Namur Thrombosis and Hemostasis

Center, Université de Namur, Yvoir, Belgium

${ }^{6}$ QUALIblood SA, Namur, Belgium
}

TH Open 2018;2:e202-e209.
Address for correspondence Prof. François Mullier, PharmD, PhD, EUSPLM, Hematology Laboratory, CHU UCL Namur, Université Catholique de Louvain, Avenue G. Thérasse, 1, 5530 Yvoir, Belgium (e-mail: francois.mullier@uclouvain.be).

\begin{abstract}
Keywords

- thrombophilia

- direct oral anticoagulants

- interference

The impact of direct oral anticoagulants (DOACs) on laboratory assays used for thrombophilia testing (e.g., antithrombin, protein S, protein C, lupus anticoagulant and activated protein- $C$ resistance) is a well-known issue and may cause false-positive and -negative results. Therefore, the correct interpretation of tests that are performed in patients taking DOACs is mandatory to prevent misclassification and the subsequent clinical consequences. We aimed at evaluating the efficiency of a new and simple procedure (DOACStop ${ }^{\circledR}$; Haematex Research, Hornsby, Australia) to overcome the effect of all DOACs in reallife settings and to assess the percentage of erroneous results due to the presence of DOACs on thrombophilia screening tests. For this purpose, 135 DOAC-treated patients (38 apixaban, 40 dabigatran, 15 edoxaban, and 42 rivaroxaban) and 20 control patients were enrolled. A significant drop in apixaban, dabigatran, edoxaban, and rivaroxaban plasma concentrations following the DOAC-Stop ${ }^{\circledR}$ treatment was observed (74.8$8.2 \mathrm{ng} / \mathrm{mL}[p<0.0001]$, 95.9-4.7 ng/mL $[p<0.0001], 102.1-8.8 \mathrm{ng} / \mathrm{mL}[p=0.001]$, and $111.3-7.0 \mathrm{ng} / \mathrm{mL}[p<0.0001]$, respectively). The DOAC-Stop ${ }^{\circledR}$ treatment was mostly effective to overcome the effect of DOACs on PTT-LA, dilute Russell's viper venom time (dRVVT) screen, and dRVVT confirm tests. Using our procedures, false-positive results due to DOACs were observed only with lupus anticoagulant tests (up to $75 \%$ ) and fell to zero after the DOAC-Stop ${ }^{\circledR}$ procedure, regardless of the DOAC considered. In conclusion, the DOAC-Stop ${ }^{\circledR}$ adsorbent procedure appeared to be an effective and simple way to overcome the interference of DOAC on coagulation tests and should facilitate the interpretation of thrombophilia screening tests in patients taking DOACs.
\end{abstract}

received

January 16, 2018

accepted

April 21, 2018
DOI https://doi.org/

10.1055/s-0038-1657785. ISSN 2512-9465. (c) 2018 Georg Thieme Verlag KG Stuttgart · New York
License terms

(c) (i) 


\section{Introduction}

Direct oral anticoagulants (DOACs) including apixaban, dabigatran etexilate, edoxaban, and rivaroxaban are used worldwide since their approval in several thromboembolic disorders, including the treatment and secondary prevention of recurrent venous thromboembolism (VTE) and pulmonary embolism (PE) as well as the prevention of stroke and systemic embolism in patients with nonvalvular atrial fibrillation (NVAF). ${ }^{1-4}$

The impact of DOACs on laboratory assays used for thrombophilia testing (e.g., antithrombin, protein S, protein $C$, lupus anticoagulant, and activated protein- $C$ resistance [APC-R]) is a well-known issue and may cause false-positive and -negative results. ${ }^{5-9}$ Therefore, the correct interpretation of results that are performed in patient taking DOACs is mandatory to prevent misclassification and the subsequent clinical consequences. ${ }^{7}$

Several strategies were proposed to minimize the impact of residual DOACs on coagulation assays: (1) the use of DOACinsensitive assays, (2) the addition of idarucizumab to the plasma sample (Praxbind, Boehringer Ingelheim) to specifically neutralize the in vitro activity of dabigatran, ${ }^{10}$ or (3) missing one (for once-daily fixed-dose regimens) or two (for twice-daily fixed-dose regimens) DOAC intake in patients with low thromboembolic risk. ${ }^{6}$ However, any interruption of anticoagulation will expose the patient to an increased risk of thrombosis and residual drug levels may still affect test results. $^{7}$ Thus, none of these approaches are considered optimal and a simple way to overcome the problem would be to remove DOAC from the plasma sample without influencing its coagulant property.

The aim of this study was to evaluate the efficiency of a new and simple procedure (DOAC-Stop ${ }^{\circledR}$; Haematex Research, Hornsby, Australia) ${ }^{11}$ to overcome the effect of all DOACs in real-life settings and to assess the percentage of erroneous results due to the presence of DOACs on thrombophilia screening tests.

\section{Materials and Methods}

\section{Plasma Samples}

The study protocol was in accordance with the Declaration of Helsinki and was approved by the Medical Ethical Committee of the CHU UCL Namur, Université Catholique de Louvain (Yvoir, Belgium, approval number 31/2016). Plasma samples from 135 DOAC-treated patients (38 apixaban, 40 dabigatran, 15 edoxaban, and 42 rivaroxaban) and from 20 patients without any anticoagulant (controls) were collected between August 2014 and January 2018. The study population displayed the following characteristics: 73 females and 82 males aged 20 to 92 years (mean age $=70$ years). None of these patients were known to be LA positive. Blood was taken by venipuncture in the antecubital vein and collected into $0.109 \mathrm{M}$ sodium citrate $(9: 1 \mathrm{v} / \mathrm{v})$ tubes (Vacuette, Greiner Bio-One, Courtaboeuf, France) using a 21-gauge needle (Greiner Bio-One). Platelet-poor plasma (PPP) was obtained from the supernatant fraction of the blood tubes after a double centrifugation for 15 minutes at 2,000 $g$ at room temperature. Immediately after centrifugation, PPP from the 155 patients were frozen at $-80^{\circ} \mathrm{C}$. Samples were thawed and heated to $37^{\circ} \mathrm{C}$ for 5 minutes just before experiment.

\section{Thrombophilia Testing}

Protein S (antigenic assay, STA-Liatest Free Protein S; Diagnostica Stago, Asnières, France), protein C (chromogenic assay, STA-Stachrom Protein C, Diagnostica Stago), antithrombin activity (thrombin based-assay, STA-Stachrom AT III, Diagnostica Stago), and APC-R (Pefakit APC-R factor V Leiden using factor V-deficient plasma; DSM, Basel, Switzerland) were assayed on a STA-R MAX analyzer (Diagnostica Stago). The dilute Russell's viper venom time (dRVVT) screen and confirm (STA-Staclot dRVV Screen and Confirm, Diagnostica Stago) and the aPTT sensitive to lupus anticoagulants (PTTLA, Diagnostica Stago) were assayed on the KC10 coagulometer (Amelung GmbH, Lemgo, Germany). LA was defined as (1) a prolongation of screening tests (low phospholipid [PL] concentration; dRVVT and/or PTT-LA), (2) a partial or no correction of the prolonged clotting time after mixing patient's plasma with normal pool plasma, and (3) a decrease in the prolonged clotting time with a confirmatory test (high PL concentration). ${ }^{12,13}$ A dRVVT screen/dRVVT confirm ratio was also calculated. The following cutoff values were used for LA screening: PTT-LA $=41$ seconds ( $\mathrm{s}$ ); dRVVT screen $=44$ seconds; and [dRVVT screen/dRVVT confirm ratio] $=1.2$. Normal ranges for protein S, protein C, antithrombin activity, and APC-R were 50 to $134 \%$ for women and 70 to $148 \%$ for men, 70 to $120 \%, 80$ to $120 \%$, and $>2$, respectively. ${ }^{14,15}$

\section{Direct Oral Anticoagulant Measurement}

Concentrations of dabigatran were estimated using one Ecarin chromogenic assay (STA-ECA-II, Diagnostica Stago), and concentrations of apixaban, edoxaban, and rivaroxaban with the corresponding procedure using the chromogenic assay (STA-liquid anti-Xa, Diagnostica Stago). All these procedures were performed on the STA-R MAX analyzer (Diagnostica Stago). The limit of quantification of the corresponding apixaban, dabigatran, edoxaban, and rivaroxaban assays were $15,27,20$, and $25 \mathrm{ng} / \mathrm{mL}$, respectively. ${ }^{16-19}$

\section{DOAC-Stop ${ }^{\circledR}$ Treatment}

Thrombophilia screening tests were performed before and after the addition of adsorbent tablets (DOAC-Stop ${ }^{\circledR}$; Haematex Research, Hornsby, Australia), according to the manufacturer's instructions and depending on the available plasma volume. ${ }^{11}$ Briefly, one tablet of DOAC-Stop ${ }^{\circledR}$ designed to adsorb DOACs is added to $1 \mathrm{~mL}$ of plasma. Thereafter, the sample is gently mixed for 5 minutes and spun for 2 minutes at 2,000 $\mathrm{g}$ to precipitate DOACs with these adsorbent tablets. Finally, the supernatant supposed to be free from DOACs is collected to be further analyzed. The composition of DOAC-Stop ${ }^{\circledR}$ is Haematex proprietary information. Concentrations of apixaban, dabigatran, edoxaban, and rivaroxaban were also assayed before and after the DOAC-Stop ${ }^{\circledR}$ procedure. The DOAC-Stop ${ }^{\circledR}$ treatment in plasma samples without DOAC or anti-Xa activity was found to minimally affect the aPTT and PT. ${ }^{11,20}$ 


\section{Statistical Analysis}

False-positive LA results caused by DOACs were compared with the results obtained after the DOAC-Stop ${ }^{\circledR}$ treatment. A paired $t$-test was used in case of passed normality test and a Wilcoxon matched-pairs signed rank test in case of failed normality test (D’Agostino-Pearson normality test). A $p$-value $<0.05$ was considered as statistically significant. The concept of reference change value (RCV) used to detect minimal difference between two measurements was also employed to assess significant clinical changes after the DOAC-Stop ${ }^{\circledR}$ treatment. The RCV combined the analytical imprecision $\left(\mathrm{CV}_{\mathrm{A}}\right)$ and the intraindividual coefficient of variation $\left(\mathrm{CV}_{\mathrm{I}}\right)$ and was calculated by the following equation: $\left[R C V=2^{1 / 2} \times Z(1.96\right.$ for a probability of $95 \%) \times\left(\mathrm{CV}_{\mathrm{A}}^{2}+\right.$ $\left.\left(V_{I}^{2}\right)^{1 / 2}\right] \cdot{ }^{21}$ Biological variation data $\left(C_{I}\right)$ were found in the literature. $^{22,23}$ GraphPad Prism 6.0e (California, United States) was used to perform statistical analysis.

\section{Results}

Plasma concentrations of apixaban, dabigatran, edoxaban, and rivaroxaban before DOAC-Stop ${ }^{\circledR}$ treatment varied from 10 to $316 \mathrm{ng} / \mathrm{mL}, 2$ to $406 \mathrm{ng} / \mathrm{mL}, 21$ to $354 \mathrm{ng} / \mathrm{mL}$, and 7 to $456 \mathrm{ng} / \mathrm{mL}$, respectively. A significant drop in apixaban, dabigatran, edoxaban, and rivaroxaban concentrations following the DOAC-Stop ${ }^{\circledR}$ treatment was also observed (from 74.8 to $8.2 \mathrm{ng} / \mathrm{mL}[p<0.0001]$, from 95.9 to $4.7 \mathrm{ng} / \mathrm{mL}$ [ $p<0.0001]$, from 102.1 to $8.8 \mathrm{ng} / \mathrm{mL}[p=0.001]$, and from 111.3 to $7.0 \mathrm{ng} / \mathrm{mL}[p<0.0001]$, respectively; -Fig. 1). The residual level of each DOAC was lower than the limit of quantification of the corresponding apixaban, dabigatran, edoxaban, and rivaroxaban assays. ${ }^{16-19}$

The DOAC-Stop ${ }^{\circledR}$ treatment was mostly effective to overcome the effect of DOACs on PTT-LA, dRVVT screen, and dRVVT confirm tests (-Table 1 and - Fig. 2). False-positive results were observed only with LA tests (up to 75\%) and fell to zero after the DOAC-Stop ${ }^{\circledR}$ procedure, regardless of the DOAC considered (-Table $\mathbf{2}$ ).

Significant differences following the DOAC-Stop ${ }^{\circledR}$ procedure were also observed for the protein $S$ (dabigatran, $p=0.005$ ) and antithrombin activity (apixaban and edoxaban, $p=0.03$ and $p=0.01$ ). However, differences obtained before and after the DOAC-Stop ${ }^{\circledR}$ treatment were always below the RCV, whatever the DOAC tested. The clinical impact is therefore not relevant (-Fig. 2).
Except for rivaroxaban ( $p=0.98$ ), a significant difference was observed for APC-R. The most obvious difference was pointed out in the dabigatran group (mean absolute difference of 2.0).

No significant changes were observed in the control group.

\section{Discussion}

Our observations confirmed that APC-R, PTT-LA, dRVVT screen, dRVVT confirm, and dRVVT ratio could be influenced by DOACs and that false-positive LA results were encountered with all DOACs. ${ }^{5-7,24}$ The DOAC-Stop ${ }^{\circledR}$ treatment appeared to be an effective way to overcome the effect of DOACs on these aforementioned tests. Furthermore, the DOAC-Stop ${ }^{\circledR}$ procedure did not significantly affect all thrombophilia screening tests in control patients.

The impact of DOACs on these tests is a well-known issue, but the concentrations at which thrombophilia assays are impacted are not well defined yet and few data are available for edoxaban. Nevertheless, it is not recommended to perform LA testing in patients taking DOACs, as these may cause false-positive results in a concentration-dependent manner. ${ }^{8,25}$ It is recommended to stop taking DOACs at the time of thrombophilia testing (for at least 2 days or at trough concentration) to overcome the interference. ${ }^{6,7,25,26}$ However, the discontinuation of the treatment is not clinically recommended ${ }^{7}$ and a high variability of DOACs trough levels has been reported. ${ }^{27}$ Moreover, patients may also choose not to stop their DOAC treatment (or forget to stop) before thrombophilia testing, which could lead to wrong diagnosis and clinical consequences. ${ }^{7,9}$ Some authors recommended to detect LA using taipan snake venom time (TSVT), Ecarin clotting time (ECT), or textarin clotting time (TCT) as they are not affected by anti-Xa drugs. ${ }^{7,25,28-30}$ However, these alternatives are not readily available in clinical practice ${ }^{6,7}$ and are only appropriate for anti-Xa drugs, thus requiring different procedures depending on the drug.

Our results showed that DOACs had a higher impact on the dRVVT screen assay compared with PTT-LA and dRVVT ratio. First, false-positive results were already encountered at concentration as low as 20,23,21, and $54 \mathrm{ng} / \mathrm{mL}$ of apixaban, dabigatran, edoxaban, and rivaroxaban, respectively. Second, the mean relative decrease following the DOAC-Stop ${ }^{\circledR}$ treatment was higher for dRVVT screen (26.8, 47.5, 36.4, and $46.9 \%$ for apixaban, dabigatran, edoxaban, and rivaroxaban,
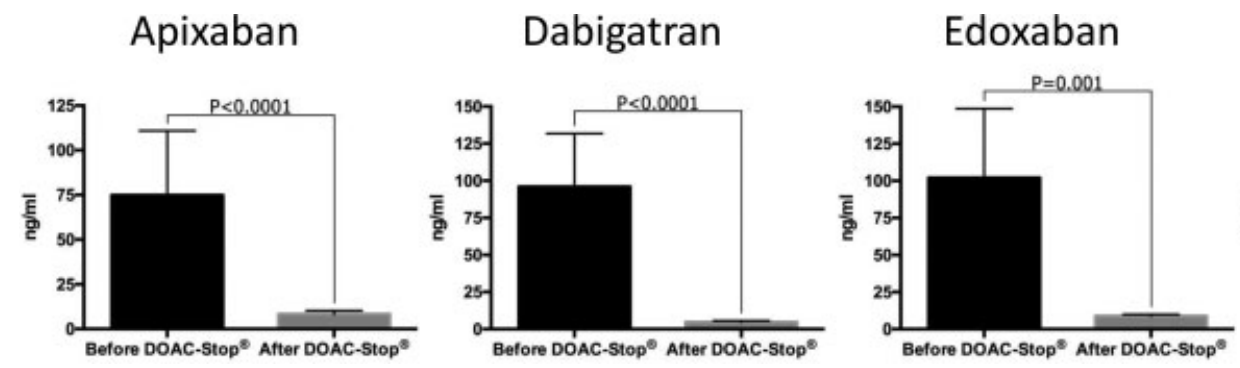

\section{Rivaroxaban}

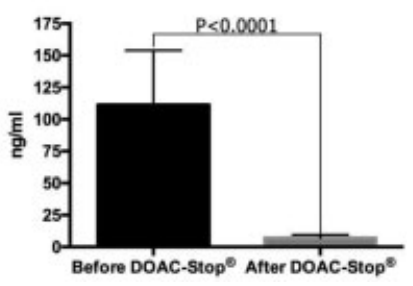

Fig. 1 Impact of the DOAC-Stop ${ }^{\circledR}$ adsorbent treatment on apixaban, dabigatran, edoxaban, and rivaroxaban concentrations. The mean (and 95\% confidence interval) of each direct oral anticoagulant is presented before and after the DOAC-Stop ${ }^{\circledR}$ treatment. 


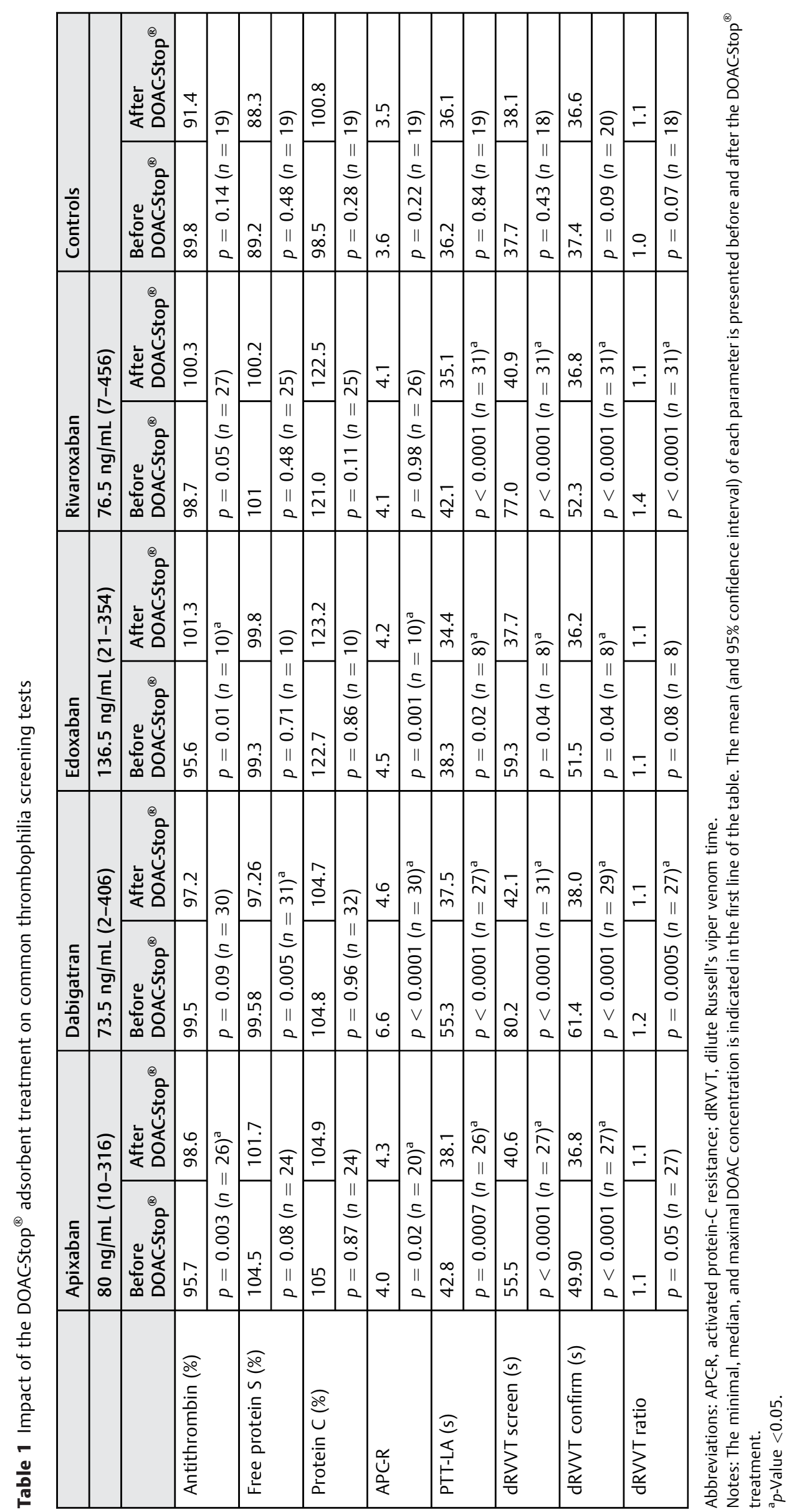



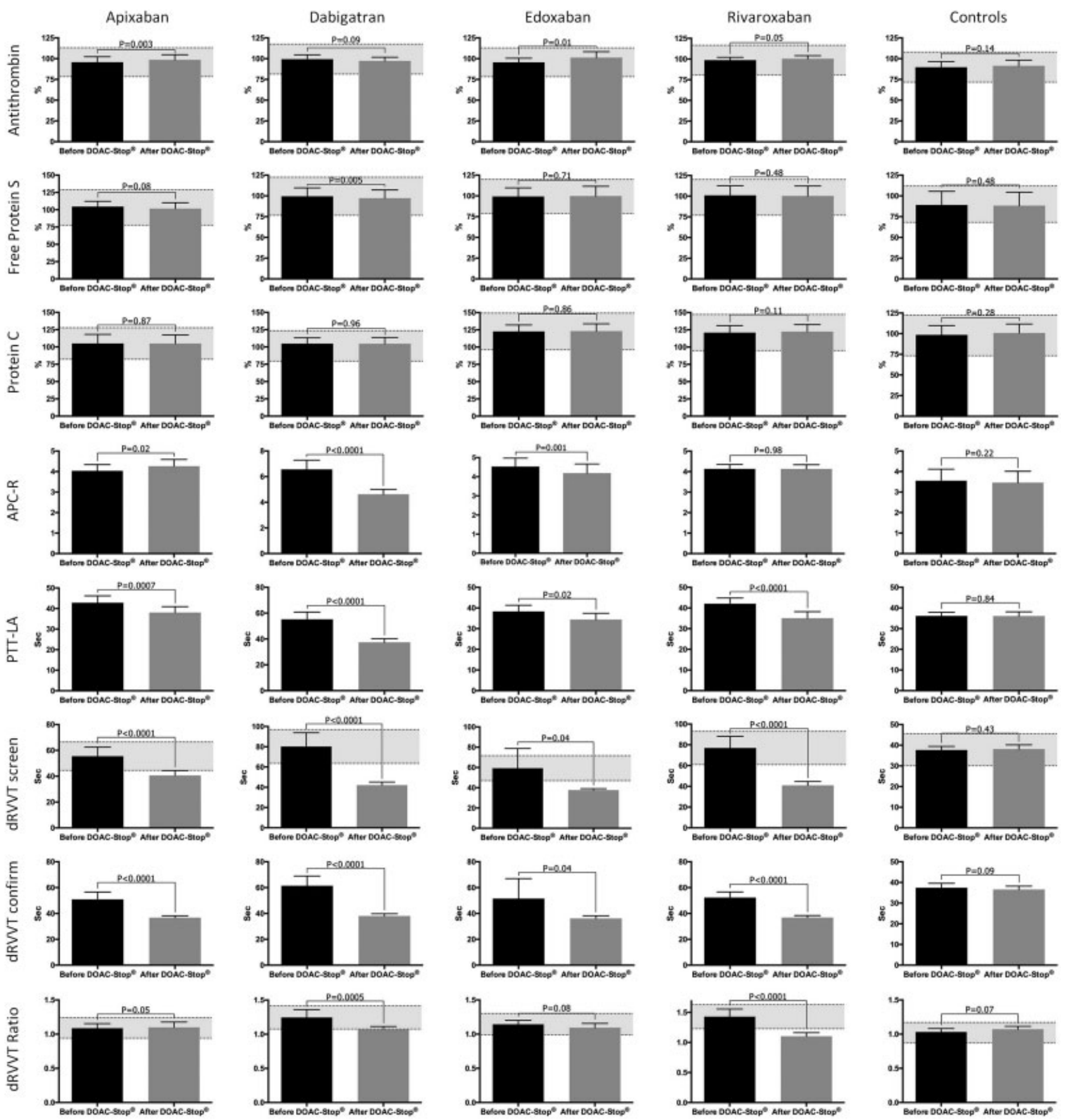

Fig. 2 Impact of the DOAC-Stop ${ }^{\circledR}$ adsorbent treatment on common thrombophilia screening tests. The gray zone corresponds to the reference change value interval of each test. The mean (and 95\% confidence interval) of each parameter is presented before and after the DOAC-Stop ${ }^{\circledR}$ treatment.

respectively) compared with PTT-LA (11.0, 32.2, 10.2, and $16.6 \%)$ and dRVVT confirm $(26.3,38.1,29.7$, and $29.6 \%$;

-Tables 1 and 2).

Third, the number of false-positive values was higher for dRVVT screen compared with PTT-LA and dRVVT ratio whatever the DOAC considered (-Table 2). These observations are consistent with recent publications showing that the dRVVT screen is the most sensitive test to the presence of DOACs. $^{24,25}$ False-positive results for all LA tests (PTT-LA, dRVVT screen, dRVVT confirm, and dRVVT ratio) were encountered regardless of the DOAC considered. Except for rivaroxaban, differences between dRVVT ratio values before and after the DOAC-Stop ${ }^{\circledR}$ treatment (dRVVT screen/dRVVT confirm) were all included in the RCV interval found in the literature. This must be explained by the fact that both dRVVT screen and dRVVT confirm are influenced by DOAC's presence in a proportional way. Therefore, a normal dRVVT ratio does not exclude the interference of DOAC.

Proteins $\mathrm{S}$ and $\mathrm{C}$ may be measured by three different methods: clot-based, antigenic, or chromogenic. Only clot- 
Table 2 False-positive LA results caused by DOACs

\begin{tabular}{|l|l|l|l|l|l|}
\hline & Apixaban & Dabigatran & Edoxaban & Rivaroxaban & Controls \\
\hline & $\begin{array}{l}\mathbf{8 0} \mathrm{ng} / \mathrm{mL} \\
(10-316)\end{array}$ & $\begin{array}{l}73.5 \mathrm{ng} / \mathrm{mL} \\
(2-406)\end{array}$ & $\begin{array}{l}136.5 \mathrm{ng} / \mathrm{mL} \\
(21-354)\end{array}$ & $\begin{array}{l}76.5 \mathrm{ng} / \mathrm{mL} \\
(7-456)\end{array}$ & \\
\hline PTT-LA (s) & $8 / 26(30.8 \%)$ & $19 / 27(70.4 \%)$ & $2 / 8(25 \%)$ & $11 / 31(35.5 \%)$ & $0 / 19(0 \%)$ \\
& From $26 \mathrm{ng} / \mathrm{mL}$ & From $33 \mathrm{ng} / \mathrm{mL}$ & From 43 ng/mL & From $23 \mathrm{ng} / \mathrm{mL}$ & \\
\hline dRVVT screen (s) & $11 / 27(40.7 \%)$ & $22 / 31(71.0 \%)$ & $6 / 8(75 \%)$ & $20 / 31(64.5 \%)$ & $0 / 18(0 \%)$ \\
& From $20 \mathrm{ng} / \mathrm{mL}$ & From $23 \mathrm{ng} / \mathrm{mL}$ & From $21 \mathrm{ng} / \mathrm{mL}$ & From $54 \mathrm{ng} / \mathrm{mL}$ & \\
\hline dRVVT ratio & $1 / 27(3.7 \%)$ & $7 / 27(26 \%)$ & $1 / 8(12.5 \%)$ & $16 / 31(51.6 \%)$ & $0 / 18(0 \%)$ \\
& From $20 \mathrm{ng} / \mathrm{mL}$ & From $16 \mathrm{ng} / \mathrm{mL}$ & From $199 \mathrm{ng} / \mathrm{mL}$ & From $65 \mathrm{ng} / \mathrm{mL}$ & \\
\hline
\end{tabular}

Abbreviation: dRVVT, dilute Russell's viper venom time.

Notes: The following cutoffs were used to calculate the number of false-positives values: PTT-LA = 41 seconds; dRVVT screen = 44 seconds; and [dRVVT screen/dRVVT confirm ratio] $=1.2$.

based methods would be affected by DOACs. ${ }^{5,6,8,24}$ As we have used an antigenic assay for protein $S$ and a chromogenic assay for protein $C$, it explains that the results were not overestimated before the DOAC-Stop ${ }^{\circledR}$ treatment. It is also reassuring to note the absence of significant difference after the DOAC-Stop ${ }^{\circledR}$ procedure when applied on the controls which suggests that this product could be used without affecting both proteins $S$ and $C$. This information is useful for practical reasons, as we showed that the DOAC-Stop ${ }^{\circledR}$ treatment does not require slitting the sample into two aliquots (one treated and the other not treated by DOACStop $\left.{ }^{\circledR}\right)$.

The APC-R methods based on the aPTT and using factor Vdeficient plasma are mostly affected by all DOACs. ${ }^{5,6,24,31}$ However, it is known that rivaroxaban does not interfere with the Pefakit APC-R factor V Leiden (prothrombinasebased assay) used in this study, ${ }^{6,32,33}$ while the dabigatran and edoxaban do. ${ }^{8,34,35}$ Accordingly, we found a significant decrease following the DOAC-Stop ${ }^{\circledR}$ procedure for dabigatran (ratio from 6.6 to $4.6, p<0.0001$ ) and to a lesser extent for edoxaban (ratio from 4.5 to $4.2, p=0.001$ ). No significant decrease was found for rivaroxaban (-Table 1 and -Fig. 2 ). Interestingly, the DOAC-Stop ${ }^{\circledR}$ treatment did not decrease the APC-R of patients taking apixaban.

The antithrombin activity is not affected by the presence of direct Xa inhibitors (apixaban, edoxaban, and rivaroxaban) when measured with a thrombin-based assay. ${ }^{5-7,36}$ As observed for protein S and C, the DOAC-Stop ${ }^{\circledR}$ procedure did not significantly affect the antithrombin activity given that we used a thrombin-based assay. ${ }^{5-7,36}$ Although we used a thrombin-based antithrombin assay, no significant difference for dabigatran following the DOAC-Stop ${ }^{\circledR}$ treatment was observed. According to the in vitro study of Douxfils et al, dabigatran started to interfere with antithrombin at higher concentration ( $>100 \mathrm{ng} / \mathrm{mL}$ ) in a thrombinbased assay. ${ }^{37}$ The median concentration of our patient samples for dabigatran was quite low $(73.5 \mathrm{ng} / \mathrm{mL})$ and may therefore explain the absence of significant difference after the DOAC-Stop ${ }^{\circledR}$ procedure.

Thus, compared with the use of idarucizumab (Praxbind, Boehringer Ingelheim) to overcome the in vitro effect of dabigatran or the use of other alternatives for LA screening tests (e.g., TSVT, ECT, or TCT), the DOAC-Stop ${ }^{\circledR}$ procedure has the advantage to remove all types of DOACs, to be simple, cheap, and easily accessible.

Our study has some limitations. Our population did not contain factor $\mathrm{V}$ Leiden carriers, LA-positive patients, and deficient in protein $S$ and $C$. It would be useful to determine if the DOAC-Stop ${ }^{\circledR}$ treatment may have an impact on these particular patients. However, vitamin $\mathrm{K}$ antagonists are the treatment of choice for antiphospholipid syndrome, protein $\mathrm{S}$ or protein C deficiency, while DOAC's use is still controversial. $^{38-41}$ Additional studies designed to evaluate the efficiency of DOAC-Stop ${ }^{\circledR}$ treatment with a larger range of DOAC's concentration on more coagulation tests (including clotting factors and instruments using optical clot detection) will also be useful. Biological variation data $\left(\mathrm{CV}_{\mathrm{I}}\right)$ obtained from the publication of de Maat et al were determined with the same reagents and on a similar platform (STA Compact analyzer, Diagnostica Stago). ${ }^{23}$ However, the $\mathrm{CV}_{\mathrm{I}}$ provided by Shou et al were obtained with different settings (ACLTOP 700 analyzer, Instrumentation Laboratory, Bedford, MA). ${ }^{22}$ Therefore, the RCV used in this study for LA tests may vary for other platforms. Nevertheless, we did not show any falsepositive PTT-LA, dRVVT screen, and dRVVT confirm results following the DOAC-Stop ${ }^{\circledR}$ procedure. Information on biological variation in hemostasis variables (e.g., APC-R, PTT-LA, and dRVVT confirm) is still limited and need further evaluations, ${ }^{23}$ but these results are clearly encouraging.

\section{Conclusion}

This real-life study confirms that thrombophilia assays are frequently influenced by the presence of DOACs. The importance depends on the DOAC and on the assay considered. Moreover, the DOAC-Stop ${ }^{\circledR}$ adsorbent procedure appeared to be an effective and simple way to overcome the interference of DOAC on coagulation tests. Our findings should facilitate the interpretation of thrombophilia screening tests in patients taking DOACs and we suggest the use of the DOAC-Stop ${ }^{\circledR}$ treatment in clinical practice to avoid potential misclassifications and clinical consequences. 
Conflicts of Interest

None declared.

\section{Acknowledgments}

The authors would like to thank Mrs. Celia Devroye, Justine Baudar, Maité Guldenpfenning, and Morgane Emmerechts for performing some of the experiments, and Mr. Nicolas Bailly for the editing of the figures.

\section{References}

1 European Medicines Agency. Xarelto - Summary of Product Characteristics. 2017. Available at: http://www.ema.europa.eu/ docs/en_GB/document_library/EPAR_-_Product_Information/ human/000944/WC500057108.pdf. Accessed May 18, 2018

2 European Medicines Agency. Pradaxa - Summary of Product Characteristics. 2017. Available at: http://www.ema.europa.eu/ docs/en_GB/document_library/EPAR_-_Product_Information/ human/000829/WC500041059.pdf. Accessed May 18, 2018

3 European Medicines Agency. Eliquis - Summary of Product Characteristics. 2017. Available at: http://www.ema.europa.eu/docs/ en_GB/document_library/EPAR_-_Product_Information/human/ 002148/WC500107728.pdf. Accessed May 18, 2018

4 European Medicines Agency. Lixiana - Summary of Product Characteristics. 2017. Available at: http://www.ema.europa.eu/ docs/en_GB/document_library/EPAR_-_Product_Information/ human/002629/WC500189045.pdf. Accessed May 18, 2018

5 Adcock DM, Gosselin R. Direct oral anticoagulants (DOACs) in the laboratory: 2015 review. Thromb Res 2015;136(01):7-12

6 Douxfils J, Ageno W, Samama CM, et al. Laboratory testing in patients treated with direct oral anticoagulants: a practical guide for clinicians. J Thromb Haemost 2018;16(02):209-219

7 Hoxha A, Banzato A, Ruffatti A, Pengo V. Detection of lupus anticoagulant in the era of direct oral anticoagulants. Autoimmun Rev 2017;16(02):173-178

8 Lippi G, Mattiuzzi C, Favaloro EJ. Thrombophilia testing in patients taking direct oral anticoagulants. Handle with care. Diagnosis (Berl) 2014;1(04):311-312

9 Goodwin AJ, Adcock DM. Thrombophilia testing and venous thrombosis. N Engl J Med 2017;377(23):2297-2298

10 Jacquemin M, Toelen J, Schoeters J, et al. The addition of idarucizumab to plasma samples containing dabigatran allows the use of routine coagulation assays for the diagnosis of hemostasis disorders. J Thromb Haemost 2015;13(11):2087-2092

11 Exner T, Michalopoulos N, Pearce J, Xavier R, Ahuja M. Simple method for removing DOACs from plasma samples. Thromb Res 2018;163:117-122

12 Pengo V, Bison E, Banzato A, Zoppellaro G, Jose SP, Denas G. Lupus anticoagulant testing: diluted Russell Viper Venom Time (dRVVT). Methods Mol Biol 2017;1646:169-176

13 Pengo V, Tripodi A, Reber G, et al; Subcommittee on Lupus Anticoagulant/Antiphospholipid Antibody of the Scientific and Standardisation Committee of the International Society on Thrombosis and Haemostasis. Update of the guidelines for lupus anticoagulant detection. J Thromb Haemost 2009;7(10):1737-1740

14 Samama MCJ, Horellou MH, Lecompte T. Physiologie et Exploration de l'hémostase. Paris: Doin; 1990:169-170

15 Kadauke S, Khor B, Van Cott EM. Activated protein C resistance testing for factor V Leiden. Am J Hematol 2014;89(12): $1147-1150$

16 Herve T, Beaufils S, Kochan J, He L, Depasse F. Development of a new automated assay for measurement of the oral direct factor Xa inhibitor edoxaban plasma concentration. Blood 2014;124:2870

17 Gouin-Thibault I, Flaujac C, Delavenne X, et al. Assessment of apixaban plasma levels by laboratory tests: suitability of three anti-Xa assays. A multicentre French GEHT study. Thromb Haemost 2014;111(02):240-248
18 Rathbun S, Tafur A, Grant R, Esmon N, Mauer K, Marlar RA. Comparison of methods to determine rivaroxaban anti-factor Xa activity. Thromb Res 2015;135(02):394-397

19 Cini M, Legnani C, Cosmi B, et al; START-Laboratory Register. Comparison of five specific assays for determination of dabigatran plasma concentrations in patients enrolled in the START-Laboratory Register. Int J Lab Hematol 2018;40(02):229-236

20 Jacquemin M, Toelen J, Feyen L, et al. The adsorption of dabigatran is as efficient as addition of idarucizumab to neutralize the drug in routine coagulation assays. Int J Lab Hematol 2018

21 Fraser CG. Biological Variation: From Principles to Practice. Washington, DC: AACC Press; 2001

22 Shou W, Chen Q, Wu W, Cui W. Biological variations of lupus anticoagulant, antithrombin, protein $\mathrm{C}$, protein $\mathrm{S}$, and von Willebrand factor assays. Semin Thromb Hemost 2016;42(01):87-92

23 de Maat MP, van Schie M, Kluft C, Leebeek FW, Meijer P. Biological variation of hemostasis variables in thrombosis and bleeding: consequences for performance specifications. Clin Chem 2016;62 (12):1639-1646

24 Gosselin R, Grant RP, Adcock DM. Comparison of the effect of the anti-Xa direct oral anticoagulants apixaban, edoxaban, and rivaroxaban on coagulation assays. Int J Lab Hematol 2016;38(05):505-513

25 Antovic A, Norberg EM, Berndtsson M, et al. Effects of direct oral anticoagulants on lupus anticoagulant assays in a real-life setting. Thromb Haemost 2017;117(09):1700-1704

26 Connors JM. Thrombophilia testing and venous thrombosis. N Engl J Med 2017;377(12):1177-1187

27 Testa S, Tripodi A, Legnani C, et al; START-Laboratory Register. Plasma levels of direct oral anticoagulants in real life patients with atrial fibrillation: results observed in four anticoagulation clinics. Thromb Res 2016;137:178-183

28 Pouplard C, Vayne C, Berthomet C, Guery EA, Delahousse B, Gruel Y. The Taipan snake venom time can be used to detect lupus anticoagulant in patients treated by rivaroxaban. Int J Lab Hematol 2017;39(03):e60-e63

29 van Os GM, de Laat B, Kamphuisen PW, Meijers JC, de Groot PG. Detection of lupus anticoagulant in the presence of rivaroxaban using Taipan snake venom time. J Thromb Haemost 2011;9(08): 1657-1659

30 Arachchillage DR, Mackie IJ, Efthymiou M, Isenberg DA, Machin SJ, Cohen $\mathrm{H}$. Interactions between rivaroxaban and antiphospholipid antibodies in thrombotic antiphospholipid syndrome. J Thromb Haemost 2015;13(07):1264-1273

31 Wilmer M, Stocker C, Bühler B, Conell B, Calatzis A. Improved distinction of factor $\mathrm{V}$ wild-type and factor $\mathrm{V}$ Leiden using a novel prothrombin-based activated protein $C$ resistance assay. Am J Clin Pathol 2004;122(06):836-842

32 Gessoni G, Valverde S, Valle L, Gessoni F, Caruso P, Valle R. Lack of rivaroxaban influence on a prothrombinase-based assay for the detection of activated $C$ protein resistance: an Italian ex vivo and in vitro study in normal subjects and factor V Leiden carriers. Int J Lab Hematol 2017;39(04):418-422

33 Hillarp A, Baghaei F, Fagerberg Blixter I, et al. Effects of the oral, direct factor Xa inhibitor rivaroxaban on commonly used coagulation assays. J Thromb Haemost 2011;9(01):133-139

34 Gessoni G, Valverde S, Valle L, Caruso P, Gessoni F, Valle R. Effect of dabigatran on a prothrombinase-based assay for detecting activated protein $C$ resistance: an ex vivo and in vitro study in normal subjects and factor V Leiden carriers. Blood Transfus 2017;15(06):562-567

35 Douxfils J, Chatelain B, Chatelain C, Dogné JM, Mullier F. Edoxaban: impact on routine and specific coagulation assays. A practical laboratory guide. Thromb Haemost 2016;115(02):368-381

36 Van Blerk M, Bailleul E, Chatelain B, et al. Influence of apixaban on commonly used coagulation assays: results from the Belgian national External Quality Assessment Scheme. Int J Lab Hematol 2017;39(04):402-408

37 Douxfils J, Mullier F, Robert S, Chatelain C, Chatelain B, Dogné JM. Impact of dabigatran on a large panel of routine or specific 
coagulation assays. Laboratory recommendations for monitoring of dabigatran etexilate. Thromb Haemost 2012;107(05): 985-997

38 Betancur JF, Bonilla-Abadía F, Hormaza AA, Jaramillo FJ, Cañas CA, Tobón GJ. Direct oral anticoagulants in antiphospholipid syndrome: a real life case series. Lupus 2016;25(06):658-662

39 Dufrost V, Risse J, Zuily S, Wahl D. Direct oral anticoagulants use in antiphospholipid syndrome: are these drugs an effective and safe alternative to warfarin? A systematic review of the literature. Curr Rheumatol Rep 2016;18(12):74

40 Kunk PR, Brown J, McShane M, Palkimas S, Gail Macik B. Direct oral anticoagulants in hypercoagulable states. J Thromb Thrombolysis 2017;43(01):79-85

41 Malec K, Góralczyk T, Undas A. The use of direct oral anticoagulants in 56 patients with antiphospholipid syndrome. Thromb Res 2017;152:93-97 